\title{
52 LEVEL AND DIFFUSIVITY CHANGES IN ILLUMINANCES UNDER CLEAR SKIES
}

Jana Pulpitlova, Richard Kittler,

Masato OKi

Hiroshi Nakamura

(ÚSTARCH SAV Bratislava, Czechslovakia) (Ashikaga Institute of Tech.)(Kyushu University)

Both the level of the daylight illuminance and the diffusivity of the atmosphere are influenced by solar beam penetration, turbidity and cloud conditions.

Currently there are standardized and used only two extreme illuminance states, model of the CIE Overcast and Clear Sky. Though the standardization of the Clear sky was proposed in 70-ies there is only an expressions for the relative luminance patterns under clear sky conditions with the alternative for two different turbidities ${ }^{1}$.

Daylight measurements made recently ${ }^{2}$ enable to characterize the natural illuminances under the real sky conditions in their absolute values and under different specific turbidities and cloudiness. A general way for the analysis of the measured data is the normalization to the simultaneous extraterrestrial horizontal illuminance level. The ratio of the global to extraterrestrial illuminance level is known as the atmospheric clearness index ${ }^{3)}$ defined by:

$$
k_{v t}=\frac{E_{v h}^{g}}{E_{v o}{ }^{\star} \sin \left(r_{s}\right)}
$$

where,

$\mathrm{E}_{\mathrm{vh}}^{\mathrm{g}}=\mathrm{global}$ illuminance,

$r_{\mathrm{S}}=$ solar height,

$\mathrm{E}_{\mathrm{VO}}=$ extraterrestrial

horizontal illuminance.

$$
k_{e t}=\frac{E^{g} e h}{E_{e o}{ }^{\star} \sin \left(r_{s}\right)}
$$

where,

$\mathrm{E}^{\mathrm{g}}{ }_{\text {eh }}=$ global irradiance,

$r_{\mathrm{s}}=$ solar height,

$\mathrm{E}_{\text {eo }}=$ extraterrestrial

horizontal irradiance.

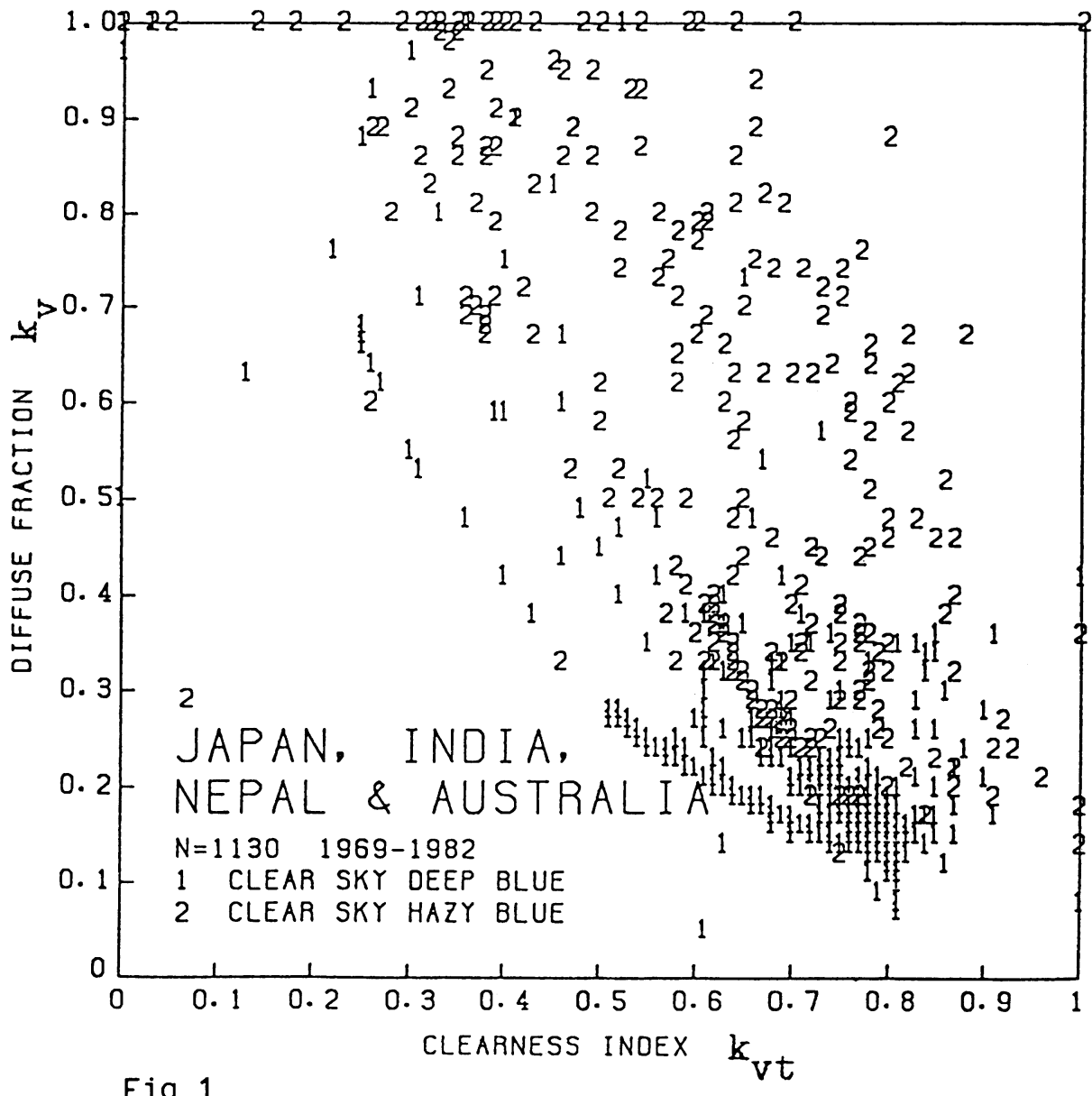

Fig. 1
晴天空における照度の拡散度と照度レベルの变動 Jana Pulpitlova、Richard kittler、沖允人、中村洋 
This ratio is expressing the effective penetration or filtering effect of the atmosphere depending on the actual solar height, thus the availability of global illuminance ( $k_{v t}$ ) or irradiance (ket).

The atmospheric diffusivity and turbidity can be expressed by the ratio of diffuse to global illuminances $\left(k_{v}\right)$ or irradiances $\left(k_{e}\right)$. Daylight measurements in Japan, India, Nepal and Australia are characterized in this system on Fig.1. However clear skies defined only subjectively are classified crude according to prevailing turbidities into two categories. The spread of measured data is quite wide and the values are covering various states from very clear and dry atmospheres (concentration of the deep blue cases in the lower part of Fig.1) through humid atmospheres $\left(k_{v t}\right.$ and $\left.k_{v}=0.7-0.8\right)$ to very turbid ones, seemingly "overcast" skies $\left(k_{\mathrm{v}}=1.0\right)$.

For verifying of the curves for the typical or characteristical clear skies (e.g. deep blue, blue, white-blue, white) we need more illuminance measurement data. Due to the greater base of measurements data on solar radiation and the validity of the $k_{t}$ kk concept in the solar radiation range we tried to compare the curve by de Brichambaut 4 ) in the $k_{e}$ and $k_{e}$ scheme on Fig. 2 with the tendency of measured illuminance data ${ }^{5}$ ) (in $k_{v}$ and $k_{v t}$ ratios).

$\mathrm{k}_{\mathrm{v}}=\frac{E_{\mathrm{vh}}^{\mathrm{d}}}{E_{\mathrm{vh}}^{\mathrm{g}}}$

where,

$\mathrm{E}^{\mathrm{d}}$ vh=diffuse illuminance,

$\mathrm{E}_{\mathrm{vh}}^{\mathrm{g}}=\mathrm{global}$ illuminance.

$k_{e}=\frac{E_{e h}^{d}}{E_{e h}^{g}}$

where,

$E^{\mathrm{d}}{ }_{\text {eh }}=$ diffuse irradiance,

$\mathrm{E}^{\mathrm{g}} \mathrm{eh}_{\mathrm{g}} \mathrm{global}$ irradiance.

\section{Acknowledgments}

The authors wish to express their thanks to the useful informations of Mr.Masanobu Nishimura, Daido Institute of Technology, Japan.

\section{References}

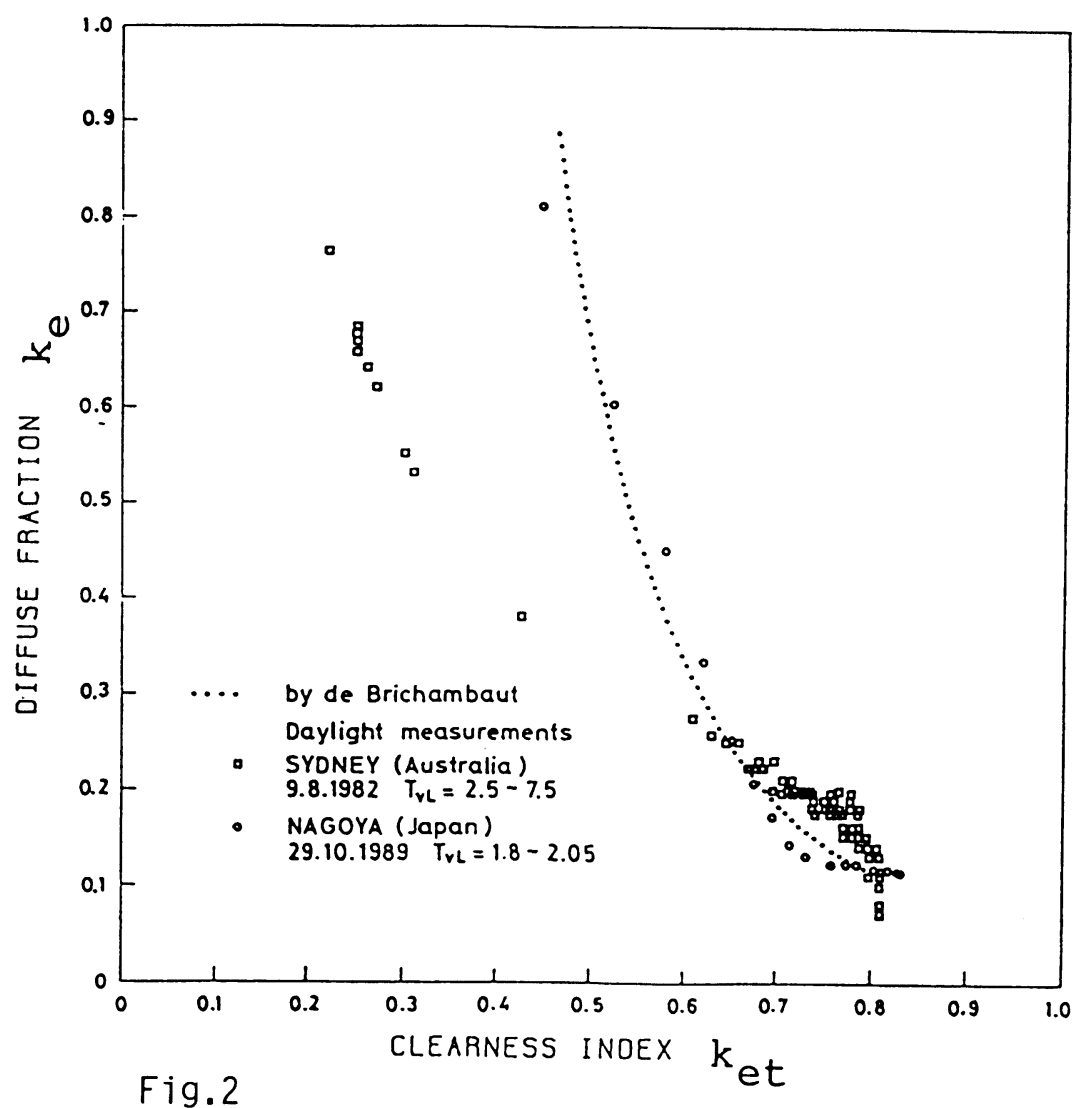

(1)CIE: Standardization of luminance distribution on clear skies, Publ. CIE No.22, Paris, 1973.

(2) Nakamura,H., Oki,M.:Study on the statistic estimation of the horizontal illuminance from unobstructed sky, Journal Light and Visual Environment, Vol.3, No.1, pp.23-31, 1979.

(3) Kittler, R.:A new concept for standardizing the daylight climate state, Proceedings of 6 th LUX Europa Congress, Vol.1, pp.303-312, Budapest, 1989.

(4) de Brichambaut,P.: La Météorologie, VI série, No.5, pp.129-158, 1976.

(5) Nishimura, M.:Personal information, Daido Institute of Technology, 1989. 